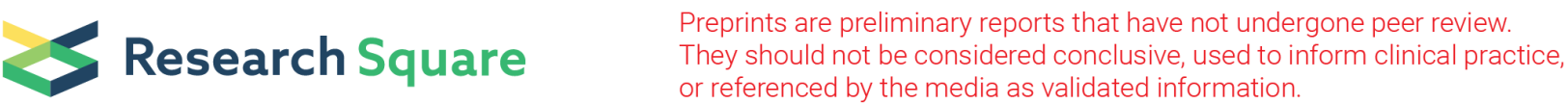

\section{Long-Term Survival in Extensive Disease Small Cell Lung Cancer Patients Treated Without Immune Checkpoint Inhibitors}

Kazushige Wakuda ( $\sim$ k.wakuda@scchr.jp )

Shizuoka Cancer Center https://orcid.org/0000-0002-6369-2388

Michitoshi Yabe

Shizuoka Cancer Center

Hiroaki Kodama

Shizuoka Cancer Center

Naoya Nishioka

Shizuoka Cancer Center

Taichi Miyawaki

Shizuoka Cancer Center

Eriko Miyawaki

Shizuoka Cancer Center

Nobuaki Mamesaya

Shizuoka Cancer Center

Haruki Kobayashi

Shizuoka Cancer Center

Shota Omori

Shizuoka Cancer Center

Akira Ono

Shizuoka Cancer Center

Hirotsugu Kenmotsu

Shizuoka Cancer Center

Tateaki Naito

Shizuoka Cancer Center

Haruyasu Murakami

Shizuoka Cancer Center

\section{Tetsuo Shimizu}

Nihon University School of Medicine

Yasuhiro Gon

Nihon University School of Medicine

Toshiaki Takahashi 


\section{Research article}

Keywords: extensive disease small-cell lung cancer, chemotherapy, long-term survival1.

Posted Date: May 18th, 2021

DOI: https://doi.org/10.21203/rs.3.rs-531143/v1

License: (c) (1) This work is licensed under a Creative Commons Attribution 4.0 International License. Read Full License 


\section{Abstract}

Background: Immune checkpoint inhibitors (ICls) combined with chemotherapy have been approved as first-line treatment for patients with untreated extensive disease-small cell lung cancer (ED-SCLC). However, there are few reports about the long-term survival in patients with ED-SCLC treated without ICls. Thus, we analyzed the long-term survival in patients with ED-SCLC.

Methods: We retrospectively examined the medical records of patients with SCLC who were treated at our hospital between September 2002 and September 2019. The main inclusion criteria were as follows: (1) histological or cytological confirmation of SCLC, (2) diagnosed with ED-SCLC, and (3) received chemotherapy, not including ICls, as the first-line treatment. To assess the trends of treatment outcomes, we compared the survival outcomes between 2002-2010 (early) and 2011-2019 (late) groups.

Results: A total of 314 patients were included in this study. Patient characteristics at the time of first-line treatment were as follows: median age was 69 years; $82 \%$ of the patients were male; and $70 \%$ had a performance status of 0 or 1 . The median follow-up time of overall survival (OS) was 7.4 years, and $89 \%$ of the patients died. The median progression-free survival and survival time were 4.9 months and 12.1 months, respectively. Five-year survival rate was $2 \%$. There was no significant difference in survival between the early and late groups.

Conclusion: We found that the long-term survival in ED-SCLC patients treated without ICls was poor. Prior to the approval of ICl treatment for ED-SCLC, there was no improvement in the OS for approximately 20 years.

\section{Background}

Lung cancer is the most common cause of cancer-related deaths worldwide. Small-cell lung cancer (SCLC) is one of the major histological types of lung cancers and accounts for $10 \%-15 \%$ of all lung cancers[1]. Approximately $60 \%-70 \%$ of patients have extensive disease (ED)-SCLC, with a poor prognosis. Although SCLC shows high sensitivity to chemotherapy and radiotherapy, the median survival time (MST) for ED-SCLC is 8-13 months, and the two-year survival rate is only $5 \%[2]$. In the recent decades, no drug has shown promising results in improving the prognosis of patients with ED-SCLC.

In 2015, nivolumab monotherapy for patients with non-small-cell lung cancer (NSCLC) showed better survival benefits than chemotherapy[3,4]. Subsequently, many phase III trials that evaluated the efficacy of immune checkpoint inhibitors (ICls) demonstrated their clinical benefit in patients with NSCLC[5-9]. Consequently, four drugs, nivolumab, pembrolizumab, atezolizumab, and durvalumab, have been currently approved for patients with NSCLC. In case of SCLC, the efficacy of ICls has not been reported by many trials in several years. However, the IMpower 133 trial, conducted in 2018[10], compared carboplatin, etoposide, and atezolizumab with carboplatin, etoposide, and placebo for patients with previously untreated ED-SCLC, with investigator-assessed progression-free survival (PFS) and overall survival (OS) as the primary endpoints. The median PFS (mPFS) was 5.2 months in the atezolizumab 
group and 4.3 months in the placebo group (hazard ratio [HR]: 0.77, 95\% confidence interval [Cl]: 0.62$0.96, p=0.02$ ), and the MST was 12.3 months and 10.3 months, respectively (HR: $0.70,95 \%$ Cl: $0.54-$ $0.91, p=0.007)$. IMpower 133 showed that the addition of atezolizumab to chemotherapy significantly prolonged PFS and OS compared with chemotherapy alone. The CASPIAN study, a phase III study of durvalumab conducted in 2019, was designed similar to the IMpower 133 trial and reproducibly showed that the addition of $\mathrm{ICl}$ to chemotherapy was also effective in patients with ED-SCLC. Based on these two studies, many guidelines recommend atezolizumab or durvalumab combined with chemotherapy as firstline treatment for patients with ED-SCLC.

Recently, clinical trials that compared ICI monotherapy with docetaxel for NSCLC patients[11-13] reported long-term survival results, which were represented by a plateau in the right tail of the survival curve. However, the median follow-up period of the trial that evaluated the efficacy of ICl combined with cytotoxic chemotherapy in patients with NSCLC or ED-SCLC was approximately 2 years, and it is unclear whether ICl combined with cytotoxic chemotherapy shows a plateau in the right tail of the survival curve. Although the data on long-term survival in patients with ED-SCLC treated without ICls are necessary to assess the efficacy of ICls combined with chemotherapy, there are limited reports documenting these data.

\section{Methods}

\subsection{Patients}

We retrospectively analyzed data on consecutive patients with ED-SCLC treated with first-line chemotherapy between September 2002 and June 2019 from the medical records of Shizuoka Cancer Center. The recruitment criteria for this study were as follows: (1) histological or cytological confirmation of SCLC, (2) diagnosis of ED-SCLC, (3) received chemotherapy, not including ICls, as the first-line treatment, and (4) no history of interstitial lung disease. We defined sensitive relapse as treatment-free interval $\geq 90$ days.

To assess the trends of treatment outcomes, we divided the patients with ED-SCLC into two groups according to the year of the first-line treatment. The "early group" included patients treated during 20022010 and the "late group" included patients treated during 2011-2019.

\subsection{Evaluation and statistical analysis}

We evaluated the tumor response to chemotherapy in accordance with the Response Evaluation Criteria in Solid Tumors by performing chest and abdomen computed tomography, head magnetic resonance imaging, bone scintiscan, or positron emission tomography-computed tomography[14]. All categorical variables were analyzed using the chi-square test or Fisher's exact test, as appropriate. Clinical evaluation of PFS and OS after the initiation of first-line chemotherapy was conducted using the Kaplan-Meier method to assess the time of recurrence or death, respectively. Survival analyses were performed using the log-rank test. The follow-up period was also estimated using the Kaplan-Meier method. All tests were 
two-sided, and p-values $<0.05$ were considered significant. Statistical analyses were performed using the JMP software version 9.0 (SAS Institute Inc., Cary, NC) and EZR. The data cutoff date was June 30, 2020. Our study was approved by the Institutional Review Board of the Shizuoka Cancer Center.

\section{Results}

\subsection{All patients}

\subsubsection{Patient characteristics}

Between September 2002 and June 2019, a total of 314 patients with ED-SCLC were included in this study. Patient characteristics at the time of first-line treatment were as follows: median age was 69 (range, 43-89) years; $82 \%$ of the patients were males, $70 \%$ had a performance status (PS) of 0 or $1,97 \%$ were past or current smoker, $98 \%$ had stage IV disease, and $34 \%$ of the patients had brain metastasis (Table 1). 
Table 1

Patient characteristics during first-line treatment

Number of patients

$(n=314)$

Age (years)

Median

69

Range

$43-89$

$\geq 75, \mathrm{n}(\%)$

$74(24)$

Gender, n (\%)

Male

$258(82)$

Female

$56(18)$

PS at first-line treatment, $\mathrm{n}(\%)$

$0-1$

$221(70)$

$2-4$

$93(30)$

Stage at diagnosis, n (\%)

stage IV

$308(98)$

Other

$6(2)$

Smoking Status, $\mathrm{n}(\%)$

Current or Former

$306(97)$

Never

$6(2)$

Unknown

2 (1)

Metastatic site, n (\%)

Lung

$53(17)$

Pleural effusion or dissemination

$108(34)$

Brain

$108(34)$

Liver

$85(27)$

Bone

$90(29)$

Adrenal gland

$57(18)$

Abbreviations: PS: performance status 


\begin{tabular}{|ll|}
\hline & $\begin{array}{l}\text { Number of patients } \\
(\mathbf{n = 3 1 4})\end{array}$ \\
\hline Regimen of first-line treatment, $\mathrm{n}(\%)$ & $39(12)$ \\
\hline Cisplatin plus Etoposide & $87(28)$ \\
\hline Cisplatin plus Irinotecan & $155(49)$ \\
\hline Carboplatin plus Etoposide & $33(11)$ \\
\hline Other & $222(71)$ \\
\hline Subsequent chemotherapy, $n$ (\%) & $92(29)$ \\
\hline Yes & $157(50)$ \\
\hline No & $65(21)$ \\
\hline Relapse pattern of patients treated with subsequent systemic therapy, $\mathrm{n}(\%)$ & \\
\hline Sensitive relapse & \\
\hline Refractory relapse & \\
\hline Abbreviations: PS: performance status & \\
\hline
\end{tabular}

Carboplatin plus etoposide was the most commonly used drug and was administered to 155 patients (49\%) while cisplatin plus irinotecan and cisplatin plus etoposide were administered in $28 \%$ and $12 \%$ of the patients, respectively. Subsequent chemotherapy was administered in 222 patients (71\%) and amrubicin was most frequently administered drug.

\subsubsection{Efficacy}

The overall response rate (ORR) of first-line treatment was $80 \%$ in all patients with ED-SCLC (Table 2). 
Table 2

Best response to first-line treatment

\begin{tabular}{|c|c|c|c|}
\hline & Number of patients $(\mathrm{N}=314)$ & Early group $(N=127)$ & Late group $(\mathrm{N}=187)$ \\
\hline \multicolumn{4}{|l|}{ Best response, $\mathrm{n}(\%)$} \\
\hline CR & $6(2)$ & $3(2)$ & $3(2)$ \\
\hline PR & $245(78)$ & $96(76)$ & $149(80)$ \\
\hline SD & $26(8)$ & $8(6)$ & $18(10)$ \\
\hline PD & $16(5)$ & $7(5)$ & $9(5)$ \\
\hline NE & $21(7)$ & $13(11)$ & $8(4)$ \\
\hline Response rate (\%) & 80 & 78 & 81 \\
\hline$p$-value & & 0.470 & \\
\hline
\end{tabular}

The median follow-up time for OS was 7.4 years (95\% Cl: $4.7-8.9$ years), and event was observed in 280 patients (89\%). MST and mPFS was 12.1 months (95\% Cl: $10.8-13.1$ months) and 4.9 months (95\% Cl: 4.6-5.2 months), respectively (Figure 1). One-year, two-year, three-year, and five-year survival rates were $49 \%, 14 \%, 6 \%$, and $2 \%$, respectively. MST in patients with PS of $0-1$, who seemed to be included in the IMpower133 trial, was 13.4 months and five-year survival rate was only $3 \%$.

\subsection{Early group and late group}

\subsubsection{Patient characteristics}

In total, 127 and 187 patients were grouped into the early and late groups, respectively. There was no significant difference in gender, PS at first-line treatment, and smoking status between the two groups (Table 3). 
Table 3

Patient characteristics in the early and late groups

\begin{tabular}{|c|c|c|c|}
\hline & $\begin{array}{l}\text { Early } \\
\text { Group } \\
(n=127)\end{array}$ & $\begin{array}{l}\text { Late } \\
\text { Group } \\
(n=187)\end{array}$ & $\begin{array}{l}\mathrm{p}- \\
\text { value }\end{array}$ \\
\hline \multicolumn{4}{|l|}{ Age (years) } \\
\hline Median & 67 & 70 & \\
\hline Range & $43-86$ & $51-89$ & 0.017 \\
\hline$\geq 75, \mathrm{n}(\%)$ & $27(21)$ & $47(25)$ & 0.4273 \\
\hline \multicolumn{4}{|l|}{ Gender, n (\%) } \\
\hline Male & $105(83)$ & $153(82)$ & \\
\hline Female & $22(17)$ & $34(18)$ & 0.845 \\
\hline \multicolumn{4}{|l|}{ PS at first-line treatment, $\mathrm{n}(\%)$} \\
\hline $0-1$ & $90(71)$ & $131(70)$ & \\
\hline $2-4$ & $37(29)$ & $56(30)$ & 0.877 \\
\hline \multicolumn{4}{|l|}{ Stage at diagnosis, n (\%) } \\
\hline stage IV & $122(96)$ & $186(99)$ & \\
\hline Other & $5(4)$ & $1(1)$ & 0.031 \\
\hline \multicolumn{4}{|l|}{ Smoking Status, n (\%) } \\
\hline Current or Former & $123(97)$ & $183(97)$ & \\
\hline Never & $3(2)$ & $3(2)$ & \\
\hline Unknown & $1(1)$ & $1(1)$ & 0.856 \\
\hline \multicolumn{4}{|l|}{ Metastatic site, n (\%) } \\
\hline Lung & $32(25)$ & $21(11)$ & 0.001 \\
\hline Pleural effusion or dissemination & $46(36)$ & $62(33)$ & 0.575 \\
\hline Brain & $44(35)$ & $64(34)$ & 0.939 \\
\hline Liver & $31(24)$ & $54(29)$ & 0.382 \\
\hline Bone & $37(29)$ & $53(28)$ & 0.879 \\
\hline Adrenal gland & $22(17)$ & $35(19)$ & 0.753 \\
\hline
\end{tabular}

Abbreviations: PS: performance status 


\begin{tabular}{|llll|}
\hline & $\begin{array}{l}\text { Early } \\
\text { Group } \\
(\mathbf{n = 1 2 7 )}\end{array}$ & $\begin{array}{l}\text { Late } \\
\text { Group } \\
(\mathbf{n}=187)\end{array}$ & $\begin{array}{l}\text { p- } \\
\text { value }\end{array}$ \\
\hline Regimen of first-line treatment, $\mathrm{n}(\%)$ & & & \\
\hline Cisplatin plus Etoposide & $14(11)$ & $25(13)$ & \\
\hline Cisplatin plus Irinotecan & $44(35)$ & $43(23)$ & \\
\hline Carboplatin plus Etoposide & $51(40)$ & $104(56)$ & \\
\hline Other & $18(14)$ & $15(8)$ & 0.015 \\
\hline Subsequent chemotherapy, $n$ (\%) & & & \\
\hline Yes & $95(75)$ & $127(68)$ & \\
\hline No & $32(25)$ & $60(32)$ & 0.395 \\
\hline $\begin{array}{l}\text { Relapse pattern of patients treated with subsequent systemic } \\
\text { therapy, } n \text { (\%) }\end{array}$ & & & \\
\hline Sensitive relapse & $30(24)$ & $35(19)$ & \\
\hline Refractory relapse & $65(51)$ & $92(49)$ & 0.515 \\
\hline Abbreviations: PS: performance status & & & \\
\hline
\end{tabular}

Although the proportion of patients over 75 years old was not significantly different, more older patients were included in the late group. The proportion of patients with stage IV disease or lung metastasis was greater in the late group. Subsequent chemotherapy was administered in 75 patients $(75 \%)$ of the early group and 127 patients $(68 \%)$ of the late group.

\subsubsection{Efficacy}

The ORR of first-line treatment was $78 \%$ in the early group and $81 \%$ in the late group (Table 2). The MST was 13.0 months ( $95 \% \mathrm{Cl}$ : $10.5-14.6$ months) in the early group, versus 11.8 months $(95 \% \mathrm{Cl}$ : $9.4-12.9$ months) in the late group ( $p=0.18$, Figure $2 A)$. The mPFS was 4.9 months ( $95 \% \mathrm{Cl}: 4.2-5.5$ months) and 4.9 months (95\% Cl: $4.6-5.2$ months) in the early and late groups $(p=0.87$, Figure $2 B)$, respectively.

\section{Discussions}

In this study, we retrospectively analyzed the long-term survival of first-line treatment in patients with EDSCLC. Our study showed that the MST of first-line treatment was 12.1 months and the five-year survival rate was only $2 \%$. There was no significant difference in survival when comparing the treatment outcomes from 2002 to 2010 with those from 2011 to 2019. The efficacy of first-line treatment with chemotherapy alone in patients with ED-SCLC is still poor, and there has been no improvement in survival for approximately 20 years. 
Only a few drugs for SCLC patients have been approved in the last 20 years and cisplatin plus etoposide or irinotecan have been the standard treatment until recently. ICls, such as atezolizumab and durvalumab, were approved as first-line treatment for ED-SCLC patients in 2019. The follow-up period of the studies that led to the approval of ICls for patients with ED-SCLC were short, and there are limited reports on the long-term survival of ED-SCLC patients treated without ICIs. In 1995, the long-term survival of 1714 patients with SCLC were reported from nine trials[15]. This report included 886 ED-SCLC patients, and the five-year survival rate was $2.3 \%$; these results were comparable with our results. Schabath et al. reported temporal trends from 1986 to 2008 in SCLC patient survival[16]. They divided 1032 patients with EDSCLC into two groups based on the year of treatment: patients treated between 1986 and 1999 and those treated between 2000 and 2008. The five-year survival rate was significantly higher in the 2000-2008 time-period ( $8.3 \%$ vs. $11.0 \%, \mathrm{p}<0.001)$. MST increased from 11.3 months to 15.2 months between the two groups. On the other hand, Lattuca-Truc et al. reported trends in survival of SCLC patients between 1997 and 2017[17]. They included 529 patients with SCLC and compared survival between 1997-2009 (period 1) and 2010-2017 (period 2). MST was 13.2 months in period 1 and 11.2 months in period 2. Treatment period was not an independent factor associated with death when analyzed by multivariate analysis (HR: 0.82, 95\% Cl: 0.66-1.00). Oze et al. reported trends in SCLC in 1993-2006 based on Population-Based Cancer Registry data[18]. They showed that prognosis of patients with SCLC plateaued from 1999-2001 to 2002-2006. These results suggest that treatment outcomes have not improved since 2000. Patients treated from 2002 to 2019 were included in our study, and there was also no significant difference in treatment outcomes by year with chemotherapy as first-line treatment. Because our study included patients who were treated just before the ICls was approved, we think our results was an important reference for future studies evaluating the efficacy of ICls combined with chemotherapy in EDSCLC patients.

In case of NSCLC, studies have revealed that ICI monotherapy shows a plateau in the right tail of the survival curve. However, cytotoxic chemotherapy did not show a plateau, and the survival rate was close to zero. When ICl was combined with chemotherapy, it was unclear whether it shows a plateau in the right tail of the survival curve because of the short follow-up period of the study, while our study showed the long-term survival of patients with ED-SCLC without treatment with ICls. We believe our study will be an important reference for future studies on ICls combined with chemotherapy for patients with ED-SCLC.

Our study had several limitations. First, the sample size was small and this study was the result of a single-center analysis. However, our study included only patients with ED-SCLC, and there are only a few reports on ED-SCLC patients. Moreover, our study had a follow-up time of almost 7 years, which was longer than the average time-period of previous clinical trials. Based on these factors, we believe our study is very worthwhile. Second, the timing of response assessment was decided by each physician; although, this might have introduced variance of ORR and PFS, we also assessed OS, which was a reliable endpoint. Finally, this study was retrospective analysis. However, a prospective study assessing the long-term survival of patients with ED-SCLC treated without ICI is difficult. We though our results were important as real-world date of those patients. For more reliable date of long-term survival in patients with ED-SCLC, multi institutional study of ED-SCLC was warranted in the future. 


\section{Conclusion}

In conclusion, this study revealed that the long-term survival in patients with ED-SCLC treated without ICI was poor. Analysis of the survival trend for patients with ED-SCLC prior to the approval of ICI treatment revealed no improvement in patient survival. We believe our study will be an important reference for future studies evaluating the efficacy of ICls combined with chemotherapy in ED-SCLC patients.

\section{Abbreviations}

SCLC: small cell lung cancer, ED: extensive disease, MST: median survival time, NSCLC: non-small-cell lung cancer, ICl: Immune checkpoint inhibitor, PFS: progression-free survival, OS: overall survival, mPFS: median progression-free survival, HR: hazard ratio, Cl: confidence interval, PS: performance status, ORR: overall response rate

\section{Declarations}

Authors' contributions: KW conceived the study. Analyses were performed by KW. MY, HK, NN, TM, EM, $\mathrm{NM}, \mathrm{HK}$, and $\mathrm{SO}$ reviewed the results and discussion. $\mathrm{KW}$ wrote the paper with contributions from $\mathrm{AO}, \mathrm{HK}$, TN, HM, TS, YG, and TT. This article is an original research work, and all authors have read and approved the final version of the manuscript

Funding: Not applicable

Availability of data and materials: The datasets generated and/or analyzed during the current study are available from the corresponding author on reasonable request.

Ethics approval and consent to participate: Our study was approved by the Institutional Review Board of the Shizuoka Cancer Center. The need to obtain informed consent to participate was waived due to the retrospective design of this study.

Consent for publication: Not applicable

Competing interests: All authors have no conflict of interest regarding this manuscript.

Acknowledgement: Not Applicable

\section{References}

1. Lum C, Alamgeer M. (2019) Technological and Therapeutic Advances in Advanced Small Cell Lung Cancer. Cancers (Basel) 11 (10). doi:10.3390/cancers11101570.

2. Puglisi M, Dolly S, Faria A, Myerson JS, Popat S, O'Brien ME. Treatment options for small cell lung cancer - do we have more choice? Br J Cancer. 2010;102(4):629-38. doi:10.1038/sj.bjc.6605527. 
3. Borghaei H, Paz-Ares L, Horn L, Spigel DR, Steins M, Ready NE, Chow LQ, Vokes EE, Felip E, Holgado E, Barlesi F, Kohlhaufl M, Arrieta O, Burgio MA, Fayette J, Lena H, Poddubskaya E, Gerber DE, Gettinger SN, Rudin CM, Rizvi N, Crino L, Blumenschein GR Jr, Antonia SJ, Dorange C, Harbison CT, Graf Finckenstein F, Brahmer JR. Nivolumab versus Docetaxel in Advanced Nonsquamous Non-Small-Cell Lung Cancer. N Engl J Med. 2015;373(17):1627-39. doi:10.1056/NEJMoa1507643.

4. Brahmer J, Reckamp KL, Baas P, Crino L, Eberhardt WE, Poddubskaya E, Antonia S, Pluzanski A, Vokes EE, Holgado E, Waterhouse D, Ready N, Gainor J, Aren Frontera O, Havel L, Steins M, Garassino MC, Aerts JG, Domine M, Paz-Ares L, Reck M, Baudelet C, Harbison CT, Lestini B, Spigel DR.

Nivolumab versus Docetaxel in Advanced Squamous-Cell Non-Small-Cell Lung Cancer. N Engl J Med. 2015;373(2):123-35. doi:10.1056/NEJMoa1504627.

5. Reck M, Rodriguez-Abreu D, Robinson AG, Hui R, Csoszi T, Fulop A, Gottfried M, Peled N, Tafreshi A, Cuffe S, O'Brien M, Rao S, Hotta K, Leiby MA, Lubiniecki GM, Shentu Y, Rangwala R, Brahmer JR, Investigators K-. Pembrolizumab versus Chemotherapy for PD-L1-Positive Non-Small-Cell Lung Cancer. N Engl J Med. 2016;375(19):1823-33. doi:10.1056/NEJMoa1606774.

6. Gandhi L, Garassino MC. Pembrolizumab plus Chemotherapy in Lung Cancer. N Engl J Med. 2018;379(11):e18. doi:10.1056/NEJMc1808567.

7. Paz-Ares L, Luft A, Vicente D, Tafreshi A, Gumus M, Mazieres J, Hermes B, Cay Senler F, Csoszi T, Fulop A, Rodriguez-Cid J, Wilson J, Sugawara S, Kato T, Lee KH, Cheng Y, Novello S, Halmos B, Li X, Lubiniecki GM, Piperdi B, Kowalski DM, Investigators K-. Pembrolizumab plus Chemotherapy for Squamous Non-Small-Cell Lung Cancer. N Engl J Med. 2018;379(21):2040-51. doi:10.1056/NEJMoa1810865.

8. Rittmeyer A, Barlesi F, Waterkamp D, Park K, Ciardiello F, von Pawel J, Gadgeel SM, Hida T, Kowalski DM, Dols MC, Cortinovis DL, Leach J, Polikoff J, Barrios C, Kabbinavar F, Frontera OA, De Marinis F, Turna H, Lee JS, Ballinger M, Kowanetz M, He P, Chen DS, Sandler A, Gandara DR, Group OAKS. Atezolizumab versus docetaxel in patients with previously treated non-small-cell lung cancer (OAK): a phase 3, open-label, multicentre randomised controlled trial. Lancet. 2017;389(10066):255-65. doi:10.1016/S0140-6736(16)32517-X.

9. Socinski MA, Jotte RM, Cappuzzo F, Orlandi F, Stroyakovskiy D, Nogami N, Rodriguez-Abreu D, MoroSibilot D, Thomas CA, Barlesi F, Finley G, Kelsch C, Lee A, Coleman S, Deng Y, Shen Y, Kowanetz M, Lopez-Chavez A, Sandler A, Reck M, Group IMS. Atezolizumab for First-Line Treatment of Metastatic Nonsquamous NSCLC. N Engl J Med. 2018;378(24):2288-301. doi:10.1056/NEJMoa1716948.

10. Horn L, Mansfield AS, Szczesna A, Havel L, Krzakowski M, Hochmair MJ, Huemer F, Losonczy G, Johnson ML, Nishio M, Reck M, Mok T, Lam S, Shames DS, Liu J, Ding B, Lopez-Chavez A, Kabbinavar F, Lin W, Sandler A, Liu SV, Group IMS. First-Line Atezolizumab plus Chemotherapy in Extensive-Stage Small-Cell Lung Cancer. N Engl J Med. 2018;379(23):2220-9. doi:10.1056/NEJMoa1809064.

11. Antonia SJ, Borghaei H, Ramalingam SS, Horn L, De Castro Carpeno J, Pluzanski A, Burgio MA, Garassino M, Chow LQM, Gettinger S, Crino L, Planchard D, Butts C, Drilon A, Wojcik-Tomaszewska J, Otterson GA, Agrawal S, Li A, Penrod JR, Brahmer J. Four-year survival with nivolumab in patients 
with previously treated advanced non-small-cell lung cancer: a pooled analysis. Lancet Oncol. 2019;20(10):1395-408. doi:10.1016/S1470-2045(19)30407-3.

12. Herbst RS, Garon EB, Kim DW, Cho BC, Perez-Gracia JL, Han JY, Arvis CD, Majem M, Forster MD, Monnet I, Novello S, Szalai Z, Gubens MA, Su WC, Ceresoli GL, Samkari A, Jensen EH, Lubiniecki GM, Baas P. Long-Term Outcomes and Retreatment Among Patients With Previously Treated, Programmed Death-Ligand 1Positive, Advanced NonSmall-Cell Lung Cancer in the KEYNOTE-010 Study. J Clin Oncol. 2020;38(14):1580-90. doi:10.1200/JC0.19.02446.

13. von Pawel J, Bordoni R, Satouchi M, Fehrenbacher L, Cobo M, Han JY, Hida T, Moro-Sibilot D, Conkling P, Gandara DR, Rittmeyer A, Gandhi M, Yu W, Matheny C, Patel H, Sandler A, Ballinger M, Kowanetz M, Park K. Long-term survival in patients with advanced non-small-cell lung cancer treated with atezolizumab versus docetaxel: Results from the randomised phase III OAK study. Eur J Cancer. 2019;107:124-32. doi:10.1016/j.ejca.2018.11.020.

14. Therasse P, Arbuck SG, Eisenhauer EA, Wanders J, Kaplan RS, Rubinstein L, Verweij J, Van Glabbeke M, van Oosterom AT, Christian MC, Gwyther SG. New guidelines to evaluate the response to treatment in solid tumors. European Organization for Research and Treatment of Cancer, National Cancer Institute of the United States, National Cancer Institute of Canada. J Natl Cancer Inst. 2000;92(3):205-16.

15. Lassen U, Osterlind K, Hansen M, Dombernowsky P, Bergman B, Hansen HH. Long-term survival in small-cell lung cancer: posttreatment characteristics in patients surviving 5 to $18+$ years-an analysis of 1,714 consecutive patients. J Clin Oncol. 1995;13(5):1215-20. doi:10.1200/JC0.1995.13.5.1215.

16. Schabath MB, Nguyen A, Wilson P, Sommerer KR, Thompson ZJ, Chiappori AA. Temporal trends from 1986 to 2008 in overall survival of small cell lung cancer patients. Lung Cancer. 2014;86(1):14-21. doi:10.1016/j.lungcan.2014.07.014.

17. Lattuca-Truc M, Timsit JF, Levra MG, Ruckly S, Villa J, Dumas I, Pinsolle J, Ferrer L, Guillem P, MoroSibilot D, Toffart AC, Multidisciplinary Thoracic Oncology Group Grenoble University Hospital F. Trends in response rate and survival in small-cell lung cancer patients between 1997 and 2017. Lung Cancer. 2019;131:122-7. doi:10.1016/j.lungcan.2019.03.028.

18. Oze I, Ito H, Nishino Y, Hattori M, Nakayama T, Miyashiro I, Matsuo K, Ito Y. Trends in Small-Cell Lung Cancer Survival in 1993-2006 Based on Population-Based Cancer Registry Data in Japan. J Epidemiol. 2019;29(9):347-53. doi:10.2188/jea.JE20180112.

\section{Figures}


Figure 1A

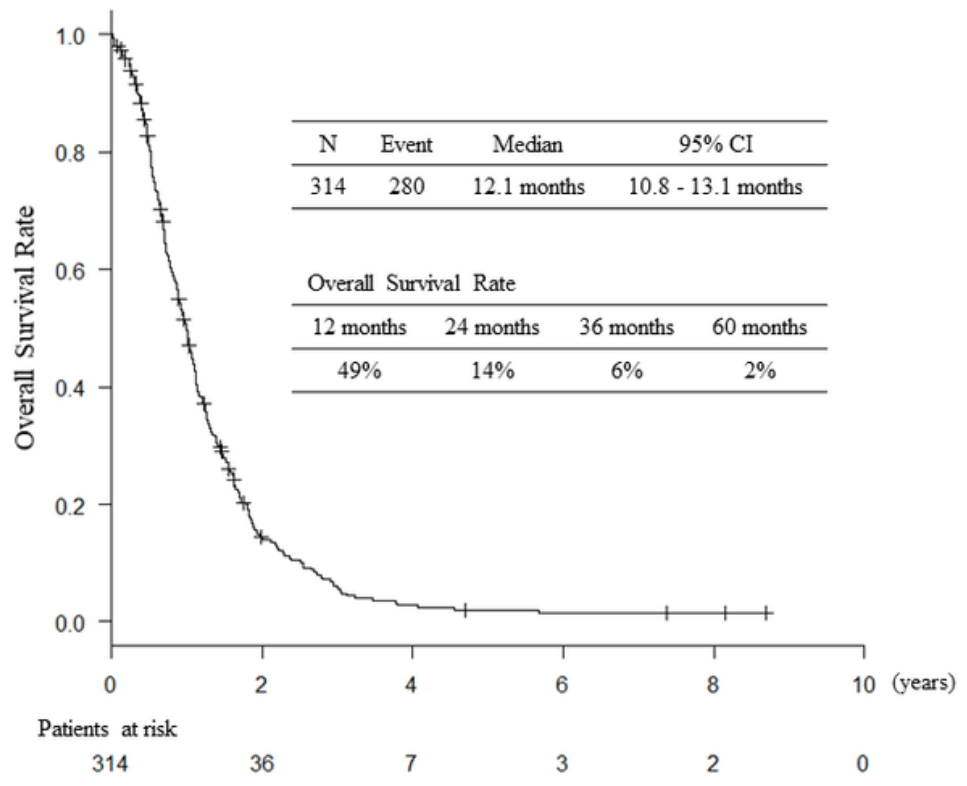

Figure 1B

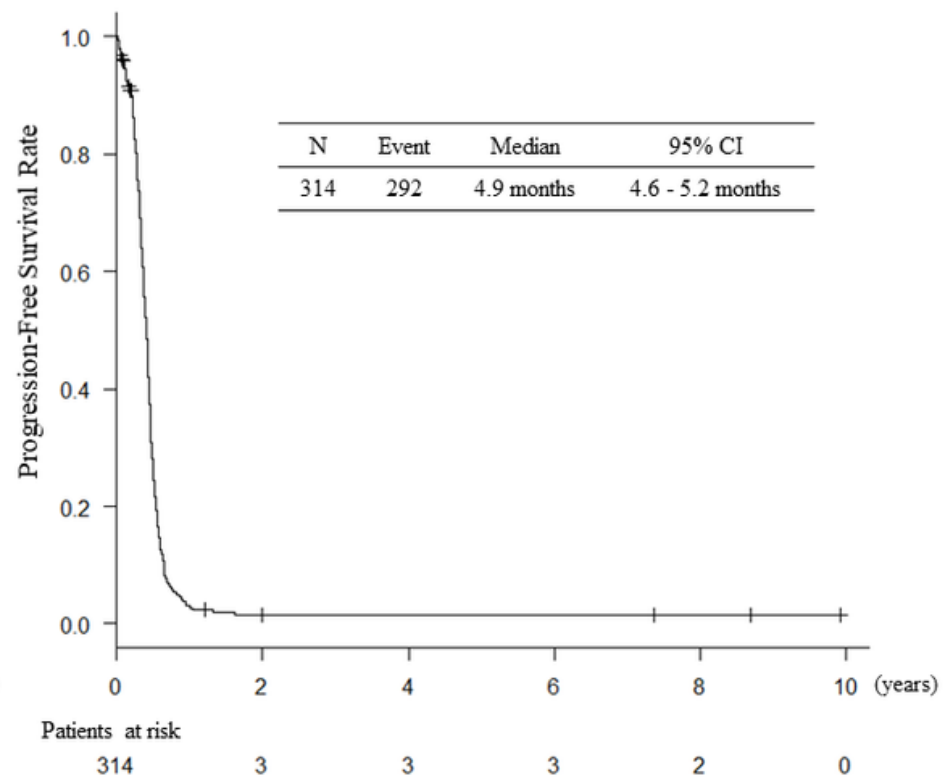

\section{Figure 1}

(A) Overall Survival, and (B) progression-free survival of patients with extensive disease small cell lung cancer

Figure 2A

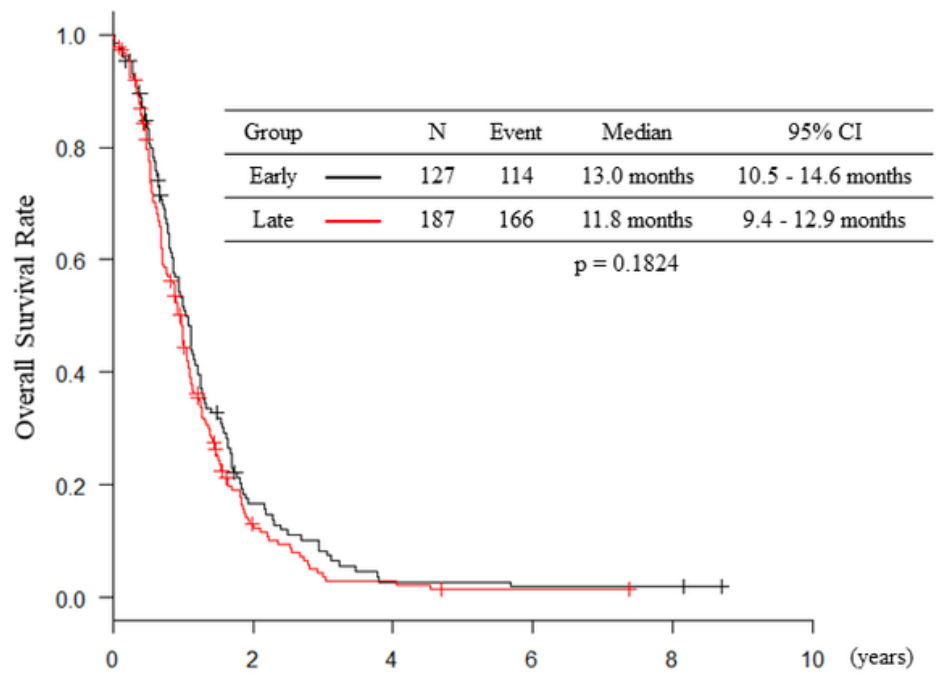

Patients at risk

Early Group 127

Late Group 187
18

18
3

4

$\begin{array}{lll}2 & 2 & 0 \\ 1 & 0 & 0\end{array}$

Figure 2B

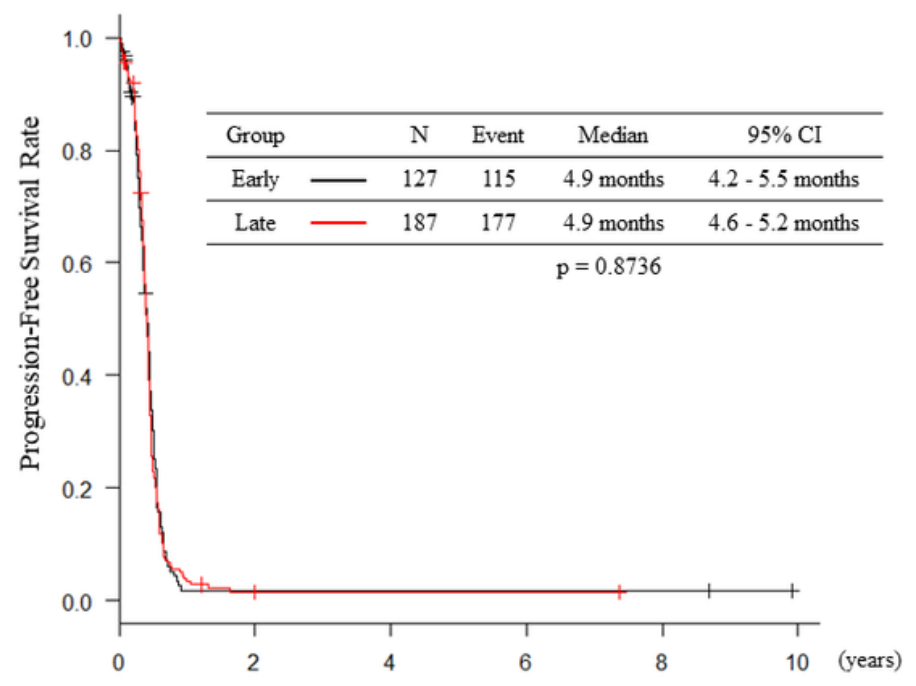

Patients at risk

$\begin{array}{lllllll}\text { Early Group } & 127 & 2 & 2 & 2 & 2 & 0 \\ \text { Late Group } & 187 & 1 & 1 & 1 & 0 & 0\end{array}$


Figure 2

(A) Overall Survival, and (B) progression-free survival in the early and late groups. 